\title{
Increase of the energy plant efficiency in special conditions of its operation
}

\author{
Razuvaev A.V. ${ }^{1,}$, Biryuk V.V. ${ }^{2}$, and Blagin E.V. ${ }^{2^{*}}$ \\ ${ }^{1}$ Balakovo Engineering-Technological Institute, 413853 Balakovo, Russian Federation \\ ${ }^{2}$ Samara University, 443086 Samara, Russian Federation
}

\begin{abstract}
This article deals with energy plant analysis during its operation in special conditions. For this purpose, modernized system of air supply and high-temperature refrigeration is suggested. Application of these systems allows to decrease specific fuel rate by $2.6 \%$.
\end{abstract}

\section{Introduction}

Development of the arrangements for cost reduction of the internal combustion engines (ICE) power plant exploitation for consumer in market conditions of Russian economics is an actual task. This fact forces ICE manufacturers to decrease cost of available products during its realization and production for expansion of the manufacturing and selling area.

Increase of the exploitation economic efficiency and durability with taking into account special condition of ICE exploitation is an actual task (besides improvement of the manufactured goods quality) which provide competitive ability in comparison with native and foreign similar products.

These tasks can be solved based on achievement of certain parameters, which determine economic efficiency of certain models of ICE. This article deals with solution of such tasks based on experience of ICE experimental research at manufacturers' facilities and during their exploitation.

Energy plants of different purpose on the base of piston ICE operate on different regimes starting from idle run and up to nominal power output, and in case of an engine used as a generator drive, ICE may operate on maximal regime, which is $110 \%$ of nominal power output [1].

For example, utilization of the energy plant as the energy source for diesel locomotive used primarily for road switching services on nominal regime requires $0.5-1 \%$ of power capacity and on partial loads and idle run - up to $60 \%$ [1]. For locomotives used in regional rails, this value reaches $3-10 \%$ on nominal regime, up to $30 \%$ on the regime of partial load and average power output is $70-80 \%$.

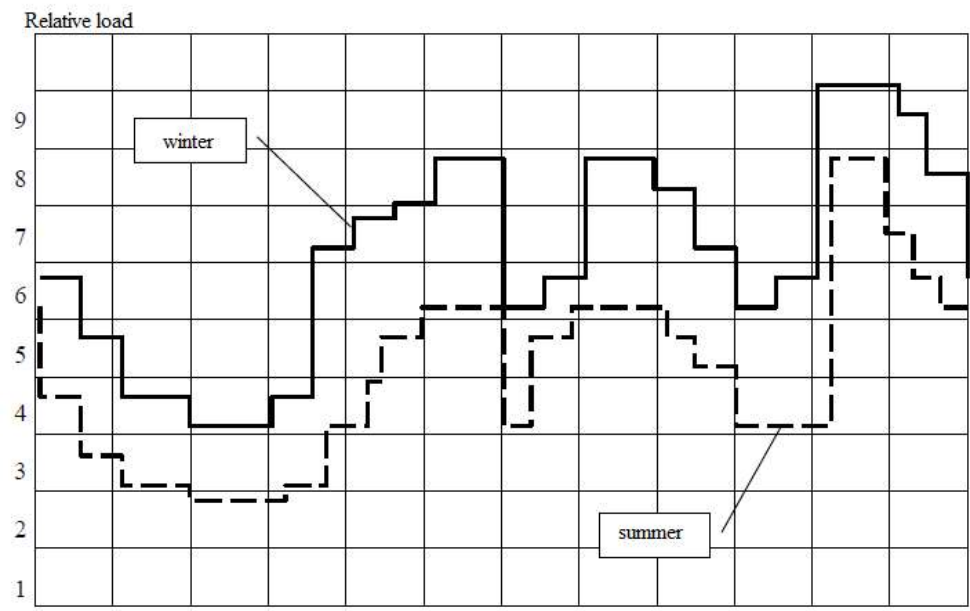

Fig.1. Plot of the day load of diesel energy plant

Figure 1 shows a plot of energy consumption by a neighbourhood [2] with developed industry and culture (theatres, cinema, etc). Usual minimum of energy consumption is located between 4 and 6 o'clock, maximum is located between 8 and 16-17o'clock with a gap from 11-12 o'clock and 13-14 o'clock with peak consumption between 19-20 o'clock and 23-24 o'clock. In different time of year, energy, water and gas consumption also varies and reaches maximum at winter

\footnotetext{
${ }^{*}$ Corresponding author: evgenyblagin@gmail.com
} 
and minimum at summer (for gas and electricity) and vice versa for water. Such periodicity is inevitable; it is utilized as a factor that allows maintaining technical condition of the energy plant on necessary level.

Exploitation of the "Slavyansk" and "Bezhitsa" ships with tree diesel generators shows that there is a possibility to use one diesel generator on the march if conditioner is not working. In case of standing in tropical climate during cargo operations, load of the energy plant was $220-230 \mathrm{~kW}$, during operation load increased up to $260-270 \mathrm{~kW}$. Thus, if two diesel generators were working, load of each one was no less than $50 \%$ of nominal power.

Due to this, if one diesel generator with load of $270 \mathrm{~kW}$ is operating instead of two operating in parallel regime, fuel economy per day can reach 0.8 tons and oil economy can reach 8-10 kg. Engine's overhauled period remains, maintenance cost is decreased. Peaks of short time load up to $300 \mathrm{~kW}$ during operation on standing in tropical climate does not allow to utilize just one diesel generator because of automatic overload control is usually set for $260-270 \mathrm{~kW}$.

Thus, for optimization of the energy plant load, it is recommended to apply automatic overload protection, set on 275$280 \mathrm{~kW}$ with 8-10 minutes exposition and at $290-300 \mathrm{~kW}$ it is necessary to turn off secondary consumers with $5-10$ seconds exposition.

Operation of energy plant of BelAZ-540 truck with D12-375E diesel generator nominal power is utilized during 5...8 minutes.

Besides, exploitation of energy plants of different purpose is performed in different climate conditions. In conditions of increased ambient temperature ICE power must be decreased according to exploitation manual.

There are also objects which has an increased resistance on suction and exhaustion in comparison with normal exploitation conditions. In this case, decrease of the maximal or nominal power of ICE is also required. Here, it should be noted that short time in overload regime requires providing of necessary power by means of power increase and this cause increased cost of the energy plant and entire facility.

Utilization of the energy plant on transport does not always allow to increase its power because it causes increase of the dimensions and weight of the vehicle.

That's why to solve these tasks and provide relatively short overload periods in relation to nominal or maximal power without decrease of the ICE durability, modernized system of air supply (MSAS) is suggested. This system considers steam injection in turbo-compressor which provides increase of its power and also increase air supply in ICE cylinders. Turbo-compressor power is increased by working fluid flow rate increase in the form of steam-gas mixture. Temperature of the steam-gas mixture is decreased because steam has lower temperature than exhaust gas. Further, increase of the air flowrate through ICE causes decrease of the specific fuel consumption and temperature of the exhaust gases, which in turn increases durability of entire power plant.

System itself consists of simple equipment such as water storage tank, which can be located in any suitable place and have almost any configuration and its volume is estimated from necessary water margin considering real operation regimes of exact energy plants. Water pumps, which provide water pumping from water margin tank into steam generator. Generated steam is pumped through the valve by duct on selected area of the turbocompressor nozzle vanes. Heat source for steam generation is a heat of the exhaust gases. Dimensions of the steam generators are determined from necessary steam flow rate for its charge in ICE.

Having such system gives an opportunity to inject small portion of steam on transient regime (i.e. during power increase) which provide transient process duration decrease and also pollution exhaust decrease from incompleteness of combustion. This fact causes increase of the energy plant ecological characteristics.

Further, analysis [4] shows that additional effect can be expected from MSAS system application. During exploitation COP of turbo compressor is decreased due to decrease of the gas turbine COP due to accumulation in its flow area of carbon and combustion incompleteness products. Observations shows that carbon layer thickness is stabilized after 400.500 hours of engine exploitation. That's why for this period charging pressure is decreased on $8-10 \%$, compressor COP - on $15 \ldots 20 \%$ which causes increase of the gas temperature on $10 \ldots 15 \%$ and specific fuel rate on $3 \ldots 6 \%(6 \ldots 11$ $\mathrm{g} / \mathrm{kW} \mathrm{h})$.

To keep gas-turbine boost in good technical condition, "Brown, Boveri", "Ishikawajima-harima" machinery companies apply cleaning of the gas-turbine boost on operating diesel [4]. This method of gas-turbine boost cleaning allow to operate without disassembling up to $12 \ldots 16$ thousand hours instead of $5 \ldots 6$ thousand hours according to manufacturer's recommendation and coincide disassembling with bearing replacement.

Methods of cleaning developed by "Brown, Boveri" and "Burmeister \& Wain" companies have a most wide distribution.

Method of "Brown, Boveri" company is that gas turbine cleaning is executed on low frequency of the diesel. Temperature of the cleaning water is kept within $323 \ldots 333 \mathrm{~K}$, cleaning periodicity is 200.250 hours and cleaning duration is $10 \ldots 20$ hours and depends on carbon accumulation degree. Cleaning is performed by clean fresh water.

Method suggested by "Burmeister \& Wain" company is that turbine and compressor cleaning is peformed by fresh water with $0.2 \ldots 0.5 \mathrm{MPa}$ pressure which is sprayed by air with $0.4 \ldots 1.0 \mathrm{MPa}$ pressure. Cleaning of the gas part and the compressor is performed under decreased rotation frequency. Cycle of cleaning for turbine is $20 \ldots .25$ minutes after 100.150 hours and for compressor is 5 minutes after $24 \ldots 48$ hours of its operation.

In Far-Eastern Shipping Company both methods of cleaning are applied with success on types "Pioneer", "Mikhail Kalinin" and "Vyborg" ships since 1970.

On the base of aforementioned we can suggest that application of MSAS similarly to cleaning of the diesel turbocompressor flow part will additionally promote increase of the diesel application efficiency in term of maintaining the given value of turbocompressor COP and increase diesel operation duration between repair. 
Another way to increase the power plant efficiency is high-temperature refrigeration (HTR). Application of HTR during ICE exploitation gives certain positive effect, which is decrease of the mass-dimensional characteristics to 8-20\%, which is important for power plants of transport vehicles and for their placement as a drive for different equipment. HTR system equipment is not complicated but this regime promotes increase of temperature of the sleeve assembly elements. This fact can slow down application of HTR because every degree increment of the refrigeration liquid temperature causes the increase of the sleeve assembly temperature on 0.8 degree. That's why application of arrangement which provide decrease of the sleeve assembly in HTR regime is an important task.

\section{Calculation algorithm}

Analysis applied above as well as founded advantages of the MSAS system testifies the reasonability of knowledge about ICE with MSAS parameters. For this reason, calculation method is suggested. Purpose of calculation is determination of the steam amount, which can be obtained from the exhaust gases heat and charged to flow area of the gas turbine of turbocompressor as well as determination of ICE parameters changed due to MSAS application. Let's estimate an amount of steam generated by heat utilization from exhaust gases considering heat utilization from refrigeration water:

$$
G_{S}=\frac{G_{g} c_{p g} T_{g 2}-G_{g} c_{p g} T_{g 3}}{r+c\left(T_{s}-T_{r w}\right)}
$$

where $T_{g 3}>423 \mathrm{~K}$ (selected from requirement for inhibition of gas duct acid corrosion);

$T_{r w}$ - reserve water temperature of the water storage is determined according to water temperature on the exit from ICE.

Then we select steam pressure and temperature correspondingly with condition $p_{s}=p_{g 1}+(0.02 \ldots 0.03) \mathrm{MPa}$. Steam flow rate value obtained from expression (1) is checked taking into account average gas pressure before the turbine pg1, steam pressure and temperature (ps and Ts) and duct geometric dimensions (1, d, Fs):

$$
G_{s}=F_{s} \sqrt{\frac{p_{s}^{2}-p_{g 1}^{2}}{\left(\lambda \frac{l}{d}+2 \ln \frac{p_{s}}{p_{g 1}}\right) \mathrm{R}_{s} T_{s}}}
$$

Diesel parameters calculation during its operation with MSAS starts with determination of the steam gas mixture flowrate through the turbine

$$
G_{s g}=\left(G_{\text {air }}+B\right)+G_{s} \text {. }
$$

For the first step air flow calculation through the diesel during its operation with MSAS and HTR is the same: $G_{\text {air }}=G_{\text {air }}^{\text {sg }}$.

Weight parts of the steam gas mixture components are found as:

$$
g_{s}=G_{s} / G_{s g} \quad g_{g}=G_{g} / G_{s g} \text {. }
$$

After this, heat capacities and gas constant of steam gas mixture are determined:

$$
c_{p}^{s g}=c_{p}^{g} g_{g}+c_{p}^{s} g_{s} \quad R_{s g}=R_{g} g_{g}+R_{s} g_{s}
$$

Temperature of the steam gas mixture on the entrance to the turbine of the turbocompressor is calculated as:

$$
T_{g 1}^{s g}=\frac{g_{s} c_{p}^{s} T_{s}+g_{g} c_{p}^{g} T_{g 1}}{g_{s} c_{p}^{s}+g_{g} c_{p}^{g}}
$$

Pressure drop of the working fluid on the turbine is proportional to its velocity and specific weight:

$\Delta p \square \frac{\omega^{2}}{2 g} \gamma \square \frac{V^{2}}{2 g} \gamma \square\left(\frac{G^{2} R^{2} T^{2}}{p^{2}}\right) \frac{p}{R T} \square \frac{G^{2} R T}{p}$

Considering this, if $\Delta p_{T}$ of the turbine operation on exhaust gases is known, for the case of MSAS:

$$
\Delta p_{t}^{s g}=\Delta p_{t} \frac{\left(G_{s g}\right)^{2} R_{s g} T_{g 1}^{s g} p_{g 1}}{\left(G_{g}\right)^{2} R_{g} T_{g 1} p_{g 1}^{s g}}
$$

In this expression for the first intermediate calculation step we accept that $p_{g 1}=p_{g}^{s g}$. Value of $\Delta p_{t}^{s g}$., founded this way, is utilized for elaboration of the value:

$$
p_{g 1}^{s g}=\Delta p_{t}^{s g}+\Delta p_{\text {exh }}
$$

Calculation by expressions (8) and (9) is executed by step by step method and is stopped when deviation in accepted and calculated values of $p_{g 1}^{s g}$ will be less than $2 \mathrm{kPa}$. Further, next values are determined:

$$
\Pi_{T}=\frac{p_{g 1}}{p_{g 2}} \text { and } \Pi_{T}^{s g}=\frac{p_{g 1}^{s g}}{p_{g 2}^{s g}}
$$


For engineering calculation it can be accepted that (it is verified by experiment) transition to MSAS is followed by almost similar increment of the expansion ratio in turbine and compression ratio in compressor. It allows to determine values of $\Pi_{c}^{s g}$ and $p_{\text {int }}^{s g}$ :

$$
\begin{aligned}
& \Pi_{c}^{s g}=\Pi_{c} \frac{\Pi_{T}^{s g}}{\Pi_{T}} \\
& p_{\text {int }}^{s g}=\Pi_{c}^{s g} p_{d} .
\end{aligned}
$$

Air flowrate change through the diesel will be proportional to change of the charge air pressure because air temperature in induction manifold is almost constant:

$$
G_{\text {air }}^{s g}=G_{\text {air }} \frac{p_{\text {int }}^{\text {sg }}}{p_{\text {int }}} .
$$

As it known, heat equivalent of turbine adiabatic work is:

$Q_{a d T}^{s g}=\frac{k_{s g}}{k_{s g}-1} R_{s g} T_{g 1}^{s g} G_{s g}\left[1-\left(\frac{1}{\Pi_{T}^{s g}}\right)^{\frac{k_{s g}}{k_{s g}-1}}\right]$.

From the other side, heat content and the exhaust gases temperature before the turbine at MSAS will be equal to:

$$
\begin{aligned}
& Q_{g 1}^{M S A S}=Q_{g 1}+\left(G_{\text {air }}^{s g}-G_{\text {air }}\right) c_{\text {pair }} \cdot T_{d} ; \\
& T_{g 1}^{M S A S}=\frac{Q_{g 1}^{M S A S}}{\left(G_{\text {air }}^{s g}+B\right) c_{\text {pair }}} .
\end{aligned}
$$

Heat content of the steam gas mixture before turbine can be found as:

$Q_{g 1}^{s g}=Q_{g 1}^{M S A S}+G_{s} c_{p s} T_{s}$.

To check, this value can also be found as:

$Q_{g 1}^{s g}=G_{s g} c_{p s g} T_{g 1}^{s g}$.

Then heat content and temperature of the steam gas flow after the turbine is calculated as:

$$
\begin{aligned}
& Q_{g 2}^{s g}=Q_{g 1}^{s g}-Q_{a g T}^{s g} ; \\
& \mathrm{T}_{g 2}^{s g}=\frac{Q_{g 2}^{s g}}{G_{s g} c_{p s g}} .
\end{aligned}
$$

Accounting founded values of $G_{\text {air }}^{s g}, T_{g 2}^{s g}, G_{s}$, diesel parameters calculations starting from expression (1) are repeated and to determine the value of $G_{s}$, values of $G_{s g}, c_{p s g}, T_{g 2}^{s g}$ are substituted instead of values of $G_{g}, c_{p g}, T_{g 2}$. Difference between the air flowrate and gas temperature between current and previous calculation must be within the range of $\pm(2 \ldots 3)$ $\mathrm{kg} / \mathrm{h}$ and $\pm(4 \ldots 5)^{\circ} \mathrm{C}$.

Value of $\alpha_{\mathrm{sg}}$ on the first step of the calculation is determined as:

$$
\alpha_{s g}=\frac{G_{a i r}^{s g}}{B \cdot 14.35}
$$

assuming constant flowrate and equal to fuel rate at diesel operation with HTR.

Diesel crank shaft frequency and average oil temperature in the lubricating system do not change after transition to MSAS, so mechanical COP can be considered constant. Thus, using known by manufacturing tests dependence $\eta_{i}=f(\varepsilon)$ value of $\eta_{I}^{s g}$ is determined according by the value of $\alpha_{\mathrm{sg}}$ founded above. Then we found the value of specific fuel rate and corresponding hour fuel rate $\mathrm{B}_{\mathrm{sg}}$. Considering founded value of $\mathrm{B}_{\mathrm{sg}}$ by expression (21) values of $\alpha_{\mathrm{sg}}, \eta_{i}^{s g}$ and $\eta_{e}^{s g}$ are specified.

Finally, specific fuel rate at MSAS is found as:

$$
B_{s g}=B \frac{\eta_{e}}{\eta_{e}^{s g}} .
$$

Example of calculation for the diesel " $6 \mathrm{ChN} 21 / 21$ " with MSAS is presented in table 1.

Initial data for the diesel calculation with MSAS are experimental values of diesel operation with HTR with load of 525,627 and $845 \mathrm{~kW}$ by load characteristics with crank shaft frequency of $\mathrm{n}=25 \mathrm{~Hz}$. 


\section{Calculation results}

Analysis of the data obtained at $845 \mathrm{~kW}$ power shows that with the calculated steam flow rate value of $0.196 \mathrm{~kg} / \mathrm{s}(10.5 \%)$, charged in the turbine of turbocompressor, decrease of the specific fuel rate is equal to $6 \mathrm{~g} / \mathrm{kW} \mathrm{h}(2.6 \%)$, hour fuel rate decrease is $5 \mathrm{~kg} / \mathrm{h}$, working fluid temperature before turbocompressor decrease is $87 \mathrm{oC}(9.3 \%)$, increase of the air flow rate is $0.092 \mathrm{~kg} / \mathrm{s}(6 \%)$ and increase of the air-fuel ratio $-0.17(8.6 \%)$.

Table 1. Calculation results.

\begin{tabular}{|c|c|c|c|c|c|c|c|}
\hline \multirow[t]{2}{*}{ Parameter } & \multirow[t]{2}{*}{ Units } & \multicolumn{2}{|c|}{$P_{e}=525 \mathrm{~kW}$} & \multicolumn{2}{|c|}{$P_{e}=627 \mathrm{~kW}$} & \multicolumn{2}{|c|}{$P_{e}=845 \mathrm{~kW}$} \\
\hline & & HTR exp. & MSAS calc. & HTR exp. & MSAS calc. & HTR exp. & MSAS calc. \\
\hline Steam flow rate & $\mathrm{kg} / \mathrm{s}$ & - & 0.123 & - & 0.1685 & - & 0.196 \\
\hline Exhaust gases flow rate & $\mathrm{kg} / \mathrm{s}$ & 1.145 & 1.19 & 1.35 & 1.41 & 1.578 & 1.671 \\
\hline Steam gas mixture flow rate & $\mathrm{kg} / \mathrm{s}$ & - & 1.31 & - & 1.578 & - & 1.867 \\
\hline Mass part of the steam in steam-gas mixture & $\%$ & - & 9.4 & - & 10.7 & - & 10.5 \\
\hline Mass part of the gas in steam-gas mixture & $\%$ & 100 & 90.6 & 100 & 89.3 & 100 & 89.5 \\
\hline Temperature before turbo compressor & $\mathrm{K}$ & 824 & 760 & 883 & 803 & 933 & 846 \\
\hline Pressure before turbo compressor & $\mathrm{MPa}$ & 0.19 & 0.199 & 0.223 & 0.234 & 0.278 & 0.298 \\
\hline Expansion ratio & & 1.82 & 1.895 & 2.065 & 2.173 & 2.574 & 2.766 \\
\hline Compression ratio in comrpessor & & 1.9 & 1.978 & 2.3 & 2.42 & 2.989 & 3.21 \\
\hline Air pressure in induct manifold & $\mathrm{MPa}$ & 0.19 & 0.1978 & 0.228 & 0.239 & 0.293 & 0.321 \\
\hline Air flow rate & $\mathrm{kg} / \mathrm{s}$ & 1.11 & 1.15 & 1.307 & 1.373 & 1.525 & 1.617 \\
\hline Temperature after the turbine & $\mathrm{K}$ & 731 & 642 & 759 & 667 & 788 & 658 \\
\hline Total air-fuel ratio & & 2.18 & 2.33 & 2.08 & 2.23 & 1.96 & 2.13 \\
\hline Indicated efficiency & $\%$ & 46.8 & 47.8 & 46 & 47.2 & 45.1 & 46.4 \\
\hline Specific effective fuel rate & $\mathrm{g} / \mathrm{kW}^{*} \mathrm{~h}$ & 240.4 & 235.3 & 233.9 & 227.9 & 230.5 & 224.5 \\
\hline
\end{tabular}

\section{Conclusion}

Analysis of the possible regimes of energy plant operating is performed on the base of piston ICE in special conditions, which differ from the conditions, specified in typical functional specifications. Opportunity of MSAS application is suggested, which allows to increase or at least maintain energy plant durability during its operation in special conditions. Calculation method is suggested which allows to determine parameters of the ICE with MSAS during its operation in special condition on the design stage. It also allows getting initial data for design and technological works by creation of MSAS system equipment. Calculation result of ICE parameters during its operation with modernized system of air supply shows that its economic efficiency on given level of power output is increased which causes increase of the exploitation economic efficiency of power plant and simultaneously decrease of hazardous working fluids exhaust together with exhaust gases from not burned fuel. Decrease of the steam-gas mixture and increase of the air flowrate through ICE promotes decrease of the temperature of sleeve assembly elements which promotes increase of the durability of power plant in special conditions. MSAS system application on ICE during its operation in special condition is justified and further development of this problem is relevant in the field of calculation of the necessary equipment parameters and algorithm determination of the design-technological parameters of the system elements.

\section{References}

1. A.V. Razuvaev, Piston internal combustion engines with high-temperature refrigeration (Saratov state technical university, Saratov, 2001) (in Russian)

2. F.L. Liventsev, Energy plants with internal combustion engines (Mashinostroenie, Leningrad, 1969) (In Russian)

3. M.K. Ovsyannikov, V.A. Petukhov, Fuel utilization efficiency in ship diesel plants (Shipping, Leningrad, 1984) (In Russian)

4. B.I. Soloviev, V.D. Ivanov, P.S. Emelianov. MAN diesel exploitation (Transport, Moscow, 1978) (in Russian)

5. A.V. Razuvaev, Turbines and Diesels (in Russian) 3(30) (2010) 